working-plan code came into operation. The pre. scribed format contains no fewer than 43 chapters, and, if the code is to be rigorously applied, it would appear that the technical staff will have even less time to undertake essential technical operations and may even be helping to dig its own grave.

So far, the Forestry Commission has been able to sell all its felled material, which amounted in 1959 60 to $20 \cdot 1$ million hoppus feet from a total area of forest of 1,283,256 acres. This presumably included the 500,000 hoppus feet blown down, equivalent roughly to the growth on 10,000 acres. While the problem of marketing is easy in those forests near industrial centres it will become acute in the next decade or two in the more remote forests, the location of which can readily be seen from an examination of the maps provided with the report. Improved methods of exploitation and transport are receiving attention and may be the solution, involving greater use of machines. Too much machinery used in forestry operations will kill employment in the country and increase it in the towns, however, which runs counter to a policy of re-population of the former. The wide scatter of the State forestry operations can be seen from the maps mentioned. This adds greatly to the risk of fire. The cost of fire protection is a heavy item in the creation from scratch of pure coniferous forests and $£ 273,000$ was spent thereon in 1960. Out of a total area of $1,618,400$ acres of forest, only 1,596 acres, or 0.1 per cent, were lost by fire, the greater part through an excess of zeal.

A paragraph describes what has been done to preserve the remnants of the natural pine forests which are owned by the Forestry Commission. It mentions "a broad belt of the eastern Highlands" where the native Scots pine is a dominant species. The meaning of this is obscure. It is claimed that investigations began in the early days of the Commis. sion into methods of treatment of the natural stands it had acquired. Details are not given, but the investigations were of the most meagre description and the main method of treatment has unfortunately been to plant up the greater part of these areas with introduced exotic conifers. The attention being devoted to other important indigenous species, especially oak and birch, is woefully inadequate, even in the research programme.

Forest research is the subject of a separate annual report. A relatively large staff is engaged in this work but its organization is far from satisfactory. It has engaged in numerous projects, many of which seem to be of minor significance. The main aim of research should undoubtedly be the improvement of sylviculture. This remark owes its origin to a statement in the report that fertilizers have been applied from the air to checked spruce stands in Cornwall, with impressive results. For how long will these results last and what was the cost ? Much research work owes its origin to faulty sylviculture, and in the improvement in their sylviculture British foresters have a great deal to learn. Forestry in Britain has suffered from a lack of trained personnel of the higher ranks and still has a long and arduous task before it is to realize its main objectives.

Regarding the financial cost to Great Britain of the establishment and working of the Forestry Commission, this is an appropriate year in which to consider this, because, when the Commission was set up in 1919, it was claimed that it would be selfsupporting in forty years' time. The total net sum spent since the start, after allowing for income other than Treasury grants, is $£ 118,219,420$, on which presumably some rate of interest is charged. Far from being now self-supporting, in 1960 payments were $£ 13,930,162$, of which only $£ 3,130,639$ was met by operational income from sales, etc. A Parliamentary vote of an additional $£ 10,702,000$ was still required. There is a somewhat naïve explanation of why forestry is not turning out to be the "counter to depopulation in the uplands" that it has for long been claimed to be. Almost any other industry could justify its existence by claiming that it gives indirect employment in other industries.

The manner of presentation of the Forestry Commission report is odd. The author of it is presumably the secretary of that body, but the report is signed by ten other persons and is presented to two Ministers in conformity with legislative requirements. To what extent each of the eleven persons in question takes responsibility for the contents remains uncertain. There is no minority report. Whether the two Ministers who receive it sit down and discuss it in detail, or whether each deals with it in turn, is doubtful. It should be mentioned, however, that the Forestry Commissioners can rely on advice from national committees, regional advisory committees, a Homegrown Timber Advisory Committee, a Committee on the Utilization of Home-grown Timber, a Mechanical Development Committee and an Advisory Committee on Forest Research. In all, between 150 and 200 persons are named in the report as having some say in the running of British forestry. This restricts the number of competent independent reviewers of their activities to a very few and makes their task invidious

M. L. ANDerson

\title{
POTATO VIRUS DISEASES
}

$\mathrm{A}^{\mathrm{s}}$ LTHOUGH conferences, especially those restricted to a particular subject (therefore small) can be very useful for providing opportunities for exchanging views, their proceedings are often superfluous. Most of the interesting information they contain has already appeared in scientific journals or in reviews as well. Recently, it has become customary to include at the end of each paper the discussion which it has stimulated, but most of it is trifling or irrelevant to the paper.

This criticism applies to the proceedings of the fourth conference on potato virus diseases, held at
Braunschweig, during September 12-17, 1960*. As it is only three years since the last conference, it is not surprising that the twenty-three papers (175 pages) it contains have very few advances to report.

Recently, Dr. Stegwee discovered that potato leaf roll virus multiplies in the vector Myzus persicae and has now reported more evidence for this. Of special interest is the finding of $P$. Ehrhardt that * Biologische Bundesanstalt für Land- und Forstwirtschaft,
Braunschweig. Proceedings of the Fourth Conference on Potato Virus Braunschweig. Proceedings of the Fourth Conference on Potato Virus $\mathbf{R}$. Bartels, V. Völk and $\mathbf{C}$. We 
infected aphids show significant decrease in oxygen consumption. V. Moericke discusses some electron micrographs of the salivary glands of $M$. persicae. (Unfortunately the micrographs are not reproduced.) Those from infected aphids contain rod-shaped particles $(50 \times 200 \mathrm{~m} \mu)$ which are suspected to have some connexion with leaf roll virus if they are not the virus particles themselves.

The papers by C. Wetter and J. Brandes report some recent work at the Biologische Bundesanstalt, Braunschweig, Germany, which increases our scope for grouping viruses on serological relationships. Using Freund's adjuvant, antisera to viruses, having rod-shaped particles, were produced with precipitation titres of up to $1: 500,000$ (unusually high titres for viruses). With such antisera it has been possible to demonstrate serological relationships between viruses previously considered unrelated.
Even more unexpected is the relationship found between viruses differing in particle-length such as between potato virus $X(520 \mathrm{~m} \mu)$ and white clover mosaic virus $(480 \mathrm{~m} \mu)$.

There are five papers on the resistance of potato varieties to virus infection, the inheritance of resistance and some practical aspects in testing for resistance. However, there is only one paper on field experiments. This may be the fault of the selection committee and not that this important kind of work is lacking.

In recent years soil-borne viruses are in the mode. In this respect the Proceedings are up to date, but of the several viruses discussed only potato rattle virus is appropriate to the conference. From the three papers attempting to review "some aspects" of virus research none contains anything new which has not been previously discussed in other review articles.
B. Kassanis

\title{
CHROMOSOMES OF NEUROSPORA
}

$\mathrm{R}$ ESEAFCH workers at the University of Texas are investigating the genetic and nutritional simplicity of the red bread mould, Neurospora, to map the locations, on particular chromosomes, of the determinants of biochemical reactions by which particular substrates are metabolized for utilization in life processes. The work is expected to lead to a clearer definition of the gene.

The red bread mould Neurospora has long been regarded as one of the most useful of genetical experimental organisms. Pure strains can be multiplied a million-fold in a fow days without genetic change. Each cell nucleus contains only a single set of genes, so recessive characters are not hidden by dominants. Neurospora can be grown in pure culture on a chemically known medium containing only sugar and a vitamin $B$ (biotin) plus a few inorganic substances. In the natural state, the mould possesses the biochemical apparatus to make, from these simple materials, all the other constituents of its cells. Thus when a genetic element is disrupted experimentally by irradiation, the mutation may be expressed and mapped in terms of the measurable changes which occur in the simple nutritional requirements of the organism.

A large group of such nutritional mutations of Neurospora have been described by R. P. Wagner, C. E. Somers and A. Bergquist at the University of Texas in Austin. Plotting the distribution of the mutations on a map of Neurospora chromosomes, Wagner's group traced them all to a limited area of the fifth chromosome. Wagner's report is preliminary, but appears to record the first demonstration, in any organism with a single or double chromosome complement, of a direct relationship between one small segment of a single chromosome and a particular set of biochemical reactions. (Damage in the segment of chromosome affected directly the transformation of precursors of two important amino-acids-isoleucine and valine.)

The results also indicate a linear arrangement of the chromosomal material, with its active elements arranged to correspond to the order of sequence of the biochemical reactions it controls.

Wagner's work is supported by the Division of General Medical Sciences and the National Cancer Institute of the U.S. Department of Health, Education and Welfare. The publication Highlights of Research Progress in General Medical Sciences, 1960, presents a summary of Wagner's work and that of other investigators who are sponsored by the Division*.

* United States Department of Health, Education and Welfare Public Health Service Publication No. 815: Highlights of Research Progress in General Medical Sciences, 1960. Items of Interest on Research Studies and Research Training Programs supported by the Bethesda 14, Md. Medical Sciences, National Institutes of Health, Bethesda 14, Md. Pp. V + 45.

\section{A CONCEPT OF ATOMIC EXISTENCE}

\author{
By Prof. W. H. WATSON \\ Department of Physics, University of Toronto
}

\begin{abstract}
TN classical terms we have a manageable concept of 1 physical existence. We represent things in a space-time map. Usually the processes by which recognizing, naming and surveying are accomplished are not shewn in this map. Nevertheless, they could be, and whenever there is doubt or unclarity in their application, they are so represented for the purpose of clarifying representation. So long as the precision of representation does not approach the limits set by the Uncertainty Principle, all the apparatus and
\end{abstract}

procedure just referred to can be used. We have confidence in ordinary language and rely on the training of physicists needed for applying it successfully in this context. The force of this consideration is illustrated in the skilful elaboration of classical explanation by Thirring in the first chapter of his Principles of Quantum Electrodynamics.

At the microphysical level, of course, there are physical impediments to applying ideas that we take for granted in the unformalized improvisation neces- 